\title{
JOSÉ MIGUEL BLANCO: ESCRITOR DE BELLAS ARTES ${ }^{1}$
}

José Miguel Blanco: a writer of fine arts

\author{
Pedro Emilio Zamorano Pérez* \\ Alberto Madrid Letelier** \\ Claudio Cortés López $* * *$
}

\section{Resumen}

El artista chileno José Miguel Blanco tuvo un rol protagónico en la escena cultural del país durante la segunda mitad del siglo XIX. Aparte de su labor escultórica, traducida en una cantidad importante de obras, una buena parte de su quehacer estuvo vinculado con la escritura de arte, lo que se materializó, principalmente, en el periódico El Taller Ilustrado, el primer medio informativo en el país dedicado exclusivamente a temas de arte, que este escultor creó y dirigió por casi cinco años. Desde esa tribuna Blanco promovió información, debates e iniciativas que favorecieron el desarrollo cultural del país. Este escultor es, sin lugar a dudas, el autor más prolífico en la escritura artística chilena de su tiempo.

Palabras clave: José Miguel Blanco, escritura artística, Chile siglo XIX, El Taller Ilustrado.

\section{Abstract}

The Chilean artist José Miguel Blanco had a protagonic role in the culture scene in the country during the second half of the 19th century. Besides his works of sculpture, reflected in an important quantity of pieces of art, a great part of his work was related to the Artistic Writing, which was materialized, mainly in the newspapers called El Taller Ilustrado, the first informative media in the country dedicated exclusively to the topics of Art, that this sculptor created and managed for almost five years. From this tribune, Blanco promoted information, debates and initiatives that contributed to the development of culture in Chile. The sculptor is, without any doubt, the most prolific author in Chilean Artistic Writing in his time.

Key words: José Miguel Blanco, ArtisticWriting, Chile 19 th, El Taller Ilustrado.

\section{ANTECEDENTES}

José Miguel Blanco (1839-1897) ${ }^{2}$ fue una de los escultores más relevantes en Chile durante la segunda mitad del siglo XIX. Según Enrique Melcherts (43),

\footnotetext{
${ }^{1}$ Este artículo se inserta en el proyecto de investigación "Construcción del gusto: la crítica de arte en Chile desde 1849 a 1970", Fondecyt No 1110647, cuyo investigador responsable es Pedro Emilio Zamorano y en donde participa, además de los coautores, el profesor Rodrigo Gutiérrez Viñuales, de la Universidad de Granada, España.

${ }^{2}$ Nació en Santiago el 16 de diciembre de 1839. Sus padres fueron don Cruz Blanco, de oficio carpintero, y la señora María Gavilán de Blanco. Sus estudios formales de escultura los inicia con
} 
este artista, desde el punto de vista cronológico, es el primer escultor chileno de la era republicana. En un documento biográfico del artista, escrito por su hijo Arturo Blanco, se le define como escultor, grabador de medallas y escritor de bellas artes.

En los primeros antecedentes biográficos del artista encontramos una vinculación con el artista araucano Pedro Churi, quien, a decir de Pablo Berrios (174), sería el primero en descubrir el talento de este niño que llegaría a ser gran escultor. Churi habría motivado a los padres de Blanco para que se incorporara a la clase que dictaba el pintor Juan Bianchi ${ }^{3}$ en el Instituto Nacional. Blanco ingresa luego a la clase de escultura que dictaba por aquella época Augusto François, quien fuera el fundador de la enseñanza de la escultura en nuestro país. Víctor Carvacho (187) integra al artista al grupo de los escultores del "Bello estilo", destacándolo como uno de los escultores nacionales más importantes del siglo XIX.

Después de sus primeros pasos artísticos en el país, en 1867, mediante Decreto, ${ }^{4}$ Blanco fue enviado a París, con el objetivo de estudiar, como señala el referido documento, "grabados, aplicados especialmente al trabajo de monedas". Con tal motivo se embarcó en Valparaíso el 10 de mayo de ese año con destino a Europa, acompañado de su profesor François. Blanco residió en Europa por nueve años; en París inicia sus estudios en el taller de grabado en medallas de Jean Baptiste Faronchon (1812-1871), quien se había destacado como escultor y grabador de medallas, además de haber obtenido el consagratorio Premio Roma, en 1835. Luego de esa experiencia inicial el escultor chileno es admitido en la Academia de Bellas Artes de París. Estando en Europa, realiza algunas de sus obras más importantes, entre ellas El padre Bartolomé de las Casas amamantado por una india, que se encuentra en el Museo O'Higginiano y de Bellas Artes de Talca.

$\mathrm{Su}$ vida en Europa fue compleja y llena de avatares. Algunos detalles de esta experiencia son informados en el epistolario que publicara Arturo Blanco, hijo del escultor, en 1907. ${ }^{5}$ A modo de ejemplo, el 19 de julio de 1870 se inicia la guerra francoprusiana, y el 18 de marzo de 1871 estalla la revolución de la comuna de París, llenándose la ciudad de conflictos y barricadas. En una carta que envía a su familia (1 de agosto de 1870), Blanco manifiesta sus aprehensiones ante la conflagración.

"Usted ya sabrá que la Francia está en guerra con la Prusia, i según se dice la guerra será terrible porque una i otra nación estaban preparándose desde hace mucho tiempo. Nuestro Chile debe contarse muy feliz de no tener guerra como estas grandes naciones, cuya gloria consiste en inventar máquinas para matarse unos a otros... Es muy triste, padre, ver todos los días salir nuevas

\footnotetext{
Augusto François en la sacristía de la capilla de la Soledad, en donde dictaba clases el maestro francés.

${ }^{3}$ Pintor italiano llegado a Chile en 1847 , a quien se le recuerda como retratista y profesor de Dibujo en el Instituto Nacional.

${ }_{5}^{4}$ Por Decreto $N^{\circ} 1.218$, del 7 de mayo de 1867, el escultor fue becado a Europa.

5 El documento, de 121 páginas, fue prologado por Juan Rafael Allende y fue editado por Imprenta "Las Artes Mecánicas", San Alfonso 47, Santiago.
} 
tropas i en ellas a muchos jóvenes conocidos, alumnos de la escuela, sobre todo" (Arturo Blanco, Cartas del escultor José Miguel Blanco, 35).

En otra misiva del 1 de septiembre de ese año el escultor manifiesta todavía una mayor desazón:

"Querido padre, la Francia, hoy día, no es la Francia de ayer. Esta maldita guerra ha trastornado al país completamente... En el momento que le escribo, está decidiéndose la suerte de este país o de la Prusia, en la frontera que separa a la Francia de la Bélgica. El combate según los diarios ha comenzado ayer, figúrese cuanta gente habrá muerto hasta el momento. Si la Francia pierde esta batalla, los prusianos se ponen en marcha para París i aquí se han tomado todas las precauciones para defenderse" (Arturo Blanco, Cartas del escultor José Miguel Blanco 37).

Estos episodios alteran la vida del escultor y junto a otros artistas, entre ellos Augusto Rodin, emigra a Bruselas, Bélgica, permaneciendo en esa ciudad por largo tiempo. Regresa a París en 1871 y desde allí viaja a distintas ciudades europeas. A comienzos de diciembre se traslada a Roma, donde reside hasta mediados de 1873. En esa ciudad tuvo contactos estrechos con la Academia Francesa de Bellas Artes en Roma, situada en el monte Pincio. En el lugar se encontró con algunos de los escultores con los cuales había compartido en París. Entre ellos Jean Antoine Injalbert (1845-1933) — maestro también del escultor chileno Simón González-y Jules Félix Coutan, el autor de la escultura en homenaje a Benjamín Vicuña Mackenna, en nuestra capital. De vuelta en París se prepara para regresar a Chile, emprendiendo el viaje de retorno a principios de noviembre de 1875. Llega a Valparaíso premunido de algunas de sus obras originales, de dibujos y libros de arte, además de muchas reproducciones en yeso.

Según su hijo Arturo, el gobierno le había ofrecido un puesto de grabador en la Casa de Moneda, promesa que no cumplió; "tuvo que luchar toda su vida, como escultor, en un país como este, sin ningún sueldo fiscal i sin bien algunos de fortuna" (Biografía del escultor Don José Miguel Blanco 15). Todos los otros maestros, antes y después de él (Nicanor Plaza, Virginio Arias, Simón González y Carlos Lagarrigue), contaron con una cátedra de escultura en la Escuela de Bellas Artes que les permitió subsistir sin mayores apremios económicos. Blanco tampoco contó con este trabajo.

\section{EL ESCRITOR}

Blanco, a quien podemos considerar en nuestro medio como el autor más prolífico de escritos de arte durante el siglo XIX, tuvo una especial sensibilidad y compromiso con la teoría y la difusión artística. En la biografia del artista, escrita por su hijo Arturo, se señala que Blanco desde muy joven manifestó su afición por la lectura y por escribir, en prosa y verso. Esta le permite desarrollar una cultura 
bastante amplia, que será la base de su trabajo posterior en el ámbito teórico. Esta veta de escritor queda ya de manifiesto al leer las cartas que enviara de Europa a su familia (1867 a 1874 y 1895). Si bien es cierto que las cartas tienen una connotación más íntima, familiar, de igual forma nos entregan detalles sobre sus estudios, relaciones, opiniones estéticas y zozobras de su vida en Europa. Las cartas, escritas la mayoría en prosa y algunas de ellas en verso, ${ }^{6}$ muestran la fluidez escritural del artista. En ellas ya se manifiesta una afición que desarrollará con profundidad a su regreso al país.

Arturo Blanco señala que a partir de 1877 el escultor se hizo escritor debido a que comprendió que en el país lo que faltaba era "Involucrar en el público el gusto por las bellas artes" (Biografia del escultor D. José Miguel Blanco 15). A partir de esa fecha generó algunas iniciativas editoriales que abordaban diferentes temas del acontecer estético y cultural. Entre ellas Las Veladas Literarias y el periódico San Lunes, creado el 11 de mayo de 1885. Este medio conoció ocho números y que publicó bajo la modalidad de ensayos artísticos. A partir de esta experiencia y con la idea de dar forma a un medio más al día con la contingencia fundó, el 6 de julio de ese mismo año, El Taller Ilustrado, la primera publicación sobre temas exclusivamente artísticos que se hace en el país. El artífice de la publicación fue Blanco, quien ofició como editor, redactor $y$, en ocasiones, ilustrador de la publicación. La portada del primer número fue ilustrada con un dibujo de la escultura El defensor de la patria (El roto chileno), de Virginio Arias. En la editorial de este número ( 6 de julio de 1885 , número 1 , no consigna número de página) Blanco fija la posición ideológica del medio: "Desde las columnas de $E l$ Taller Ilustrado trataremos de enmendar el rumbo a la crítica i de estimular a la juventud que se dedica al arte". Como señalara el periódico La Época, El Taller Ilustrado sería "Un periódico destinado a popularizar entre nosotros las obras de arte más notables, merece con sobrada justicia el decidido apoyo del público"?

Cada número, de los 183 que se publicaron a lo largo de cuatro años de circulación —el último número fue publicado el 7 de julio de 1889constaba de tres páginas con información, más una portada con dibujos litográficos que reproducían obras pictóricas o escultóricas, retratos, alegorías u otras figuras, realizadas por los mejores ilustradores de ese entonces, entre ellos Luis Fernando Rojas, el francés Luis Eugenio Lemoine, Francisco David Silva y el propio José Miguel Blanco. De Lemoine hay más información de pinturas suyas que antecedentes biográficos. Silva es una figura muy central del periódico, con contribuciones relevantes en las crónicas y traducciones del francés. Su aporte gráfico es más bien escaso. El ilustrador más destacado,

${ }^{6}$ El 24 de diciembre de 1871 envía una carta desde Roma, escrita en verso, a su hermana Dominga. Desde esa misma ciudad escribe a su madre Mariquita Gavilán de Blanco otra misiva en verso, el 17 de diciembre de 1872.

7 “El Taller Ilustrado, Editorial de La Época”, El Taller Ilustrado, número 5, 3 de agosto de 1885. 
además de Blanco, fue Luis Fernando Rojas (1854-1942), ${ }^{8}$ uno de los más importantes dibujantes y litógrafos que ha tenido Chile. Además de El Taller Ilustrado, Rojas ejerció su oficio en diferentes periódicos nacionales, entre ellos La Época, El Peneca y La Revista Cómica9 .

Después de la muerte del escultor, en La Revista Ilustrada del 15 de febrero de 1897 (no consigna página) se recordaba el aporte de la publicación y homenajeaba a su director "El Taller Ilustrado hace honor a la memoria de Blanco. Quien quiera que desee conocerle bien, tendrá que recurrir a ese libro, donde el escultor vació parte delicadísima de su espíritu”.

Sin dudas que Blanco fue el artista chileno de mayor producción teórica durante la segunda mitad del siglo XIX. A sus participaciones en cada uno de los números de $E l$ Taller Ilustrado debemos agregar varios escritos de los que nos da cuenta su hijo Arturo y que fueron difundidos en distintas publicaciones de la época; entre ellas Las Veladas Literarias, Los Tiempos y El Ferrocarril. Al respecto destacamos los siguientes textos: "Algo sobre influencia del Arte y de la Sociedad"; "Las Estatuas desde el Renacimiento hasta nuestros días"; "Proyecto de un Museo de Bellas Artes"; "Menicuccia, Reina i Decano de los modelos en Roma" (dedicado al coronel Marcos Maturana); "El Herrero Pintor Mester Queten" (dedicado al pintor Francisco David Silva); "Nuestro Cementerio, sus Mausoleos i la piedra de Rigolemu"; "Homenaje a los Héroes" (dedicado a Benjamín Vicuña Mackenna); "Dos retratos al óleo de Horacio Vernet"; "Los cuadros obsequiados al Museo de Bellas Artes por el Coronel Maturana"; "El figurero ambulante"; "El Convento y la Escuela de San Francisco" (recuerdos de la infancia); "Las Bellas Artes en Chile" (carta al presbítero don Esteben Muñoz Donoso); "Carta al Arquitecto Fermín Vivaceta", a propósito de su Proyecto de Mausoleo a las víctimas de la guerra; "Una Perla en el Fango" (respecto del descubrimiento de la Minerva de Fidias); "El gran Premio de los Artistas"; "El Arte i la Política; El retrato en la Antigüedad i en nuestros días"; "Un artista de la Provincia de Concepción en el salón de París" (Virginio Arias); "El escultor de Concepción don Virginio Arias"; "Proyecto de Reglamento para en Envío de Pensionistas a Europa"; "Los funerales de Atahualpa en el Museo de Bellas Artes" (cuadro del pintor peruano Luis Montero); "Dos artistas chilenos en París" (Arias y Lira); "Dos palabras acerca de las Bellas Artes en Chile" (carta a don Moisés Vargas); "El dibujo obligatorio"; "Monumento a Prat"; "El Museo Nacional de Bellas Artes", entre muchos otros.

\footnotetext{
${ }^{8}$ Nacido en Casablanca, en condiciones económicas precarias, emigra a Santiago para incorporarse al Instituto Nacional, en donde fue alumno de Juan Bianchi y Ernesto Kirchbach. En 1874 ingresó a la Escuela de Pintura, siendo alumno de Cosme San Martín.

${ }^{9}$ En 1875 abandona la pintura y se dedica más de lleno a la ilustración de episodios históricos, costumbristas y de personajes. Logró un singular éxito en sus dibujos de políticos y personajes, muchas veces caricaturizados, de la vida social e intelectual chilena de la época. También fueron importantes las copias que realizó de obras artísticas, muchas de las cuales están en las portadas de El Taller Ilustrado. Sus retratos, de héroes y personajes nacionales, constituyen en su obra un capítulo aparte.
} 
Según Arturo Blanco, en 1887 el escultor había reunido los datos necesarios para escribir unos Apuntes para la Historia del Arte en Chile, proyecto que comenzaría con algunas biografias de Ambrosio Santelices, Pedro Santelices (padre e hijo) e Ignacio Andía y Varela, primeros escultores nacionales de la era republicana. El proyecto, que pensaba fuera publicado en forma de libro acompañado de ilustraciones, no conoció su materialización. El trabajo se sustentaba en una investigación, proceso éste que Blanco tradujo en otro texto, "En busca de datos", que fuera publicado como artículo en El Taller Ilustrado del 31 de julio de 1887.

\section{ENCUENTROS Y DESENCUENTROS}

La actividad artística en nuestro país durante el siglo XIX estuvo marcada por las directrices del Estado y la sociedad influyente. Ello se manifiesta en el contexto de un espacio de formación casi monopólico - la Escuela de Bellas Artes-, en la circulación de la información y en la propia institucionalidad que orientaba el quehacer artístico, que se hacía representar en los diferentes consejos y comisiones que habían sido creados. En un escenario estrecho y predeterminado por preceptos académicos - legitimados por la propia "oficialidad"-, con voces potentes como las de Pedro Lira y Vicente Grez, en donde había poco espacio para la disidencia, los personalismos y las visiones divergentes tensionaban el ambiente.

José Miguel Blanco levantó una voz crítica desde las páginas de El Taller Ilustrado. Sus objeciones apuntaban a las prerrogativas y al funcionamiento que tenía la Unión Artística. ${ }^{10}$ Según él, esta institución, de carácter privado, había adquirido un protagonismo excesivo y poco transparente en la organización de los salones. El escultor, que inicialmente había aplaudido las actividades de la entidad, especialmente la construcción del edificio de la Quinta Normal, con posterioridad la criticó con vehemencia desde las páginas del periódico. Se erigen aquí dos bandos que entran en disputa. Uno, liderado por Pedro Lira, Vicente Grez y los miembros de la referida Unión Artística, versus aquellos, tales como Pascual Ortega, Cosme San Martín, Miguel Campos y Pedro León Carmona, que adherían a la figura de Blanco. Grez hacía sus críticas desde el periódico La Época, en tanto que sus detractores lo hacían desde El Taller Ilustrado. A modo de ejemplo, en una crónica de noviembre de 1887, los aliados de Blanco, liderados por Pascual Ortega, replicaban desde El Taller Ilustrado (no consigna número de página) ${ }^{11}$ un artículo de Grez "Si el señor Grez nos enseñara, soportaríamos sus golpes con santa resignación, i aún le diríamos como el filósofo de marras, pega recio pero enséñanos".

\footnotetext{
${ }^{10}$ La entidad había sido fundada en 1867 por Pedro Lira y Luis Dávila Larraín. Sus objetivos eran desarrollar las Bellas Artes en Chile y su principal realización fue la construcción de un edificio, llamado el Partenón, en la Quinta Normal de Agricultura, en donde se ubican las obras del Museo y se organizan exposiciones.

11 "El señor Vicente Grez i sus críticas de arte en La Época”, El Taller Ilustrado, número 108, 28 de noviembre de 1887 .
} 
La controvertida Unión Artística había sido autorizada por parte del gobierno para construir un local en la Quinta Normal de Agricultura, el Partenón, que sería destinado a exposiciones periódicas de pinturas y esculturas. ${ }^{12}$ Los salones 1885 y 1887, realizados en ese lugar, fueron duramente criticados por Blanco desde el periódico. Refiriéndose al Salón de 1887 señala: "El salón hizo fiasco desde su estreno. Hoi la Sociedad "Unión Artística", con la conciencia 'del deber cumplido', se disuelve o se retira a la vida privada, cediendo graciosamente al Supremo Gobierno el Salón-estufa por la modesta suma de dieciséis mil pesos" ("El Salón de la Unión Artística", El Taller Ilustrado, 28 de febrero de 1887, no consigna número de página). Efectivamente, en un decreto firmado por el presidente Balmaceda, de fecha 11 de febrero de 1887, se autoriza al Director del Tesoro para reducir a escritura pública el contrato de venta del edificio. Se fija el 1 de marzo para hacer efectivo el contrato. Blanco estimó que, de acuerdo con las condiciones que se establecían, el Salón quedaría siempre bajo la dirección más o menos directa de su fundador (Lira).

"Estos, Fabio, jai dolor! que ves ahora
Fragmentos de columnas, por el suelo,
Fueron un tiempo de las Bellas Artes
El más augusto i remonono templo.
Un Eróstrato por grabar su nombre
En los anales del pincel chileno,
De la discordia le aplicó la tea
I, ya lo vez, está como el de Efeso.
Consumatumest". ${ }^{13}$

El conflicto entre el pintor y el escultor no cesa. En El Taller Ilustrado del 13 de mayo de 1889 José Miguel Blanco, con profunda ironía, aplaude el nombramiento hecho por parte del Ministro de Justicia e Instrucción Pública de Pedro Lira como miembro de la Comisión Directiva de Bellas Artes.

"Aplaudimos de todo corazón — señala — tan acertado nombramiento, porque él viene a evitar a nuestro 'hermano de trabajo', el triste papel a que estaba condenado, cual es el de sacar la castaña por mano ajena. Nos gusta tanto la franqueza cuanto aborrecemos la hipocresía". ${ }^{14}$

Blanco, con igual ironía, lamenta que en nuestro país no haya, como en Francia, un ministerio especial de Bellas Artes, en donde se nombre a Lira como ministro y a Grez como subsecretario.

\footnotetext{
${ }^{12}$ Con tal objetivo se había expedido un decreto el 11 de julio de 1885 .

${ }^{13}$ Blanco, José Miguel, "El Salón de la Unión Artística", El Taller Ilustrado, 28 de febrero de 1887, no consigna número de página.

14 “Lasciate Ogni Speranza...", El Taller Ilustrado, 13 de mayo de 1889, no consigna número de página.
} 
"Lira ha nacido para mandar, como Grez ha nacido para obedecer. Ambos se complementarían. Lira, reconociendo su impotencia para lucir las innatas aspiraciones de mando en la capa social a que pertenece, resolvió 'descender' a los hombres de trabajo, con la seguridad de lograr sus fines. Hoi en el colmo de sus deseos, puede plajiar al monarca francés esclamando: 'El arte soi yo"." 15

Blanco veía en este nombramiento de Lira en la comisión el peligro de una gestión arbitraria, antojadiza, a favor exclusivo de sus conveniencias y redes sociales. "Lira desde el asiento que ocupará en la Comisión Directiva de Bellas Artes tendrá sobrada razón para repetir lleno de orgullo con el gran canciller: La force prime le droit (la fuerza supera al derecho)". ${ }^{16}$

Blanco advierte acerca de los poderes que el Estado confería en este nombramiento al pintor, cuestión que se traducía, según su punto de vista, en una injerencia desmedida en todos los aspectos relativos a la enseñanza, la circulación y adquisición de obras, la asignación de becas para los artistas, entre otros.

"En adelante Lira será, como ya lo es, el que elija y decrete la compra de cuadros i de estatuas; él les pondrá precio; él decretará la organización, apertura i clausura de las exposiciones i discernirá los premios, como que el jurado ha de ser nombrado por él mismo. Hará el rodeo y apartará las cabezas que irán a Europa a continuar sus estudios a expensas del erario nacional; él las hará volver cuando le dé gusto i gana; él elegirá el local en que se alzará el futuro Museo de Bellas Artes; i si los planos no son hechos por él, a lo menos le obedecerán los arquitectos; él cambiará a los profesores de la Universidad i les impondrá el método que han de enseñar a sus alumnos; él será el alma de la Revista de Bellas Artes, imprimiéndole el rumbo que más le convenga; el será, en suma, el totum potens, ante cuya grandeza i omnímodo poder, tendrán que humillarse los que han nacido para rendir culto a este becerro de oro....". ${ }^{17}$

Blanco percibía a Lira como la manzana de la discordia y como un enemigo de todos aquellos que no inclinaban la cabeza ante su obra y su figura intelectual. Señala que, gracias a la posición social que ocupa, consiguió hacerse nombrar miembro de la Comisión Directiva de Bellas Artes.

"Lo que falta a Lira (i lo que no sería raro para los que le conocemos) es que, a título de presidente de la Comisión Directiva, en vista de los inmensos servicios prestados al arte nacional, particularmente el de la 'concordia' que ha establecido entre sus hermanos de trabajo, se decrete en vida el honor de erijirse alguna media docena de estatuas que se alcen majestuosamente en nuestras plazas i paseos públicos i en cuyos pedestales

\footnotetext{
${ }^{15}$ Ibid.

${ }^{16}$ Ibid.

${ }^{17}$ Ibid.
} 
se lea el verso del Dante Alighieri con la siguiente variación: HONORATE L'ALTISIMO PITTORE". 18

De otra parte, los aliados de Pedro Lira reprochaban el tono beligerante de muchos de los escritos de Blanco aparecidos en El Taller Ilustrado. Cuestionaban que una publicación como esa, que recibía una subvención mensual de cien pesos de parte del Estado, se había transformado en un diario de pacotilla y en un órgano de opinión encargado de sembrar rencores entre los artistas nacionales y en donde el escultor Blanco ejercía opinión a voluntad.

Acerca de este debate Víctor Carvacho (188) señala que la enemistad de Blanco con Lira y Grez se tradujo, además, en un bloqueo que se hizo al escultor en lo relativo a encargos y posibilidades de circulación de su obra. Agregando que "Como escultor tuvo que vivir durante mucho tiempo de la venta de un busto de Arturo Prat, haciendo copias originales mediante vaciados". También señala la popularidad que tuvo la obra El tambor en descanso, especialmente en el contexto de la Guerra del Pacífico.

En los años de circulación de El Taller Ilustrado casi no hubo aspecto de interés en el acontecer artístico nacional que no fuera editorializado. En una crónica titulada “¿Por qué no hai arte nacional en Chile?” (noviembre de 1888) el periódico toma posición en el debate generado en el Centro de Artes i Letras acerca de la existencia o no de un arte genuinamente nacional, tema discutido, entre otros, por Enrique Cueto Guzmán, Emiliano Figueroa, Rafael Errázuriz, Ventura Blanco y Francisco Concha Castillo. Al respecto la posición del periódico fue clara. "Negar que hai arte nacional en Chile, cuando contamos con un considerable número de artistas en el país, amén los que están perfeccionando sus estudios en Europa, nos parece tan injusto como si negáramos que tenemos religión...". ${ }^{19}$

\section{LA CREACIÓN DEL MUSEO}

Otro de los temas que obsesionó a Blanco y que copó una buena parte de su capacidad escritural fue la idea de crear un museo de artes en Chile. Con tal motivo, en 1879 dio a conocer en la Revista Chilena un "Proyecto de un Museo de Bellas Artes". ${ }^{20}$ En el documento se plantea al Estado la necesidad de creación de este espacio de cultura y acerca de los beneficios que ello reportaría al país. Habla sobre algunos museos europeos, señalando que en estos "santuarios de arte" está depositada la inteligencia de sus países. A decir del escultor (Proyecto de un Museo de Bellas Artes, 238), "Los que hemos tenido la suerte de visitar i estudiar en esos

\footnotetext{
${ }^{18}$ Ibid.

19 “¿Por qué no hai arte nacional en Chile?”, El Taller Ilustrado número 157, 26 de noviembre de 1888, no consigna número de página.

${ }^{20}$ En los Anales de la Universidad de Chile, en noviembre de ese mismo año, es reproducido el Proyecto de Blanco. Luego, en diciembre, se reproduce en el Diario Oficial. Según Arturo Blanco, ello se debió a la acogida que la iniciativa había tenido por parte del gobierno.
} 
establecimientos las obras maestras que encierran; los que conocemos su utilidad i la influencia que ejercen hasta en la moral i la educación del pueblo, nos creemos con el deber de pedir a nuestro país la instalación de un Museo".

Blanco planteaba en el Proyecto conformar la colección con las obras, "cuadros, estatuas, bustos i otros objetos artísticos", que se encontraban en la Universidad de Chile, en la Biblioteca, en la Intendencia de Valparaíso, en La Moneda, en el Congreso, entre otros sitios. Según el escultor, "Con un simple decreto del señor Ministro de Instrucción Pública, en que se autorice a dos o tres personas de buena voluntad para reunir esas obras en los altos del Congreso, o en algunos de los edificios del fisco o del municipio i en el término de treinta o cuarenta días, sino antes, todo estaría arreglado" (Blanco, Proyecto de un Museo de Bellas Artes, 239). Contribuirían también a la colección los trabajos de los pensionistas que habían estado o estaban estudiando en Europa con becas de Gobierno y que estaban obligados a mandar un cuadro cada año.

Los cálculos de Blanco eran que se podrían reunir aproximadamente doscientas obras, cantidad entendida por él como suficiente como para fundar un pequeño museo. La necesidad de establecer la entidad y un lugar idóneo de funcionamiento tenía por objeto también proteger las obras de deterioros y robos. Según el artista (Blanco, Proyecto de un Museo de Bellas Artes, 241), "Mientras no se implante dicho establecimiento, todas esas obras adquiridas por el gobierno a costa de los fondos nacionales u obsequiadas por el patriotismo están bajo la inminencia de desaparecer una tras otra". Esperaba que las obras, reunidas en un solo local y con un catálogo, podrían ser conservadas con esmero, estarían a salvo de robos y deterioros y podrían ser apreciadas por el público.

La inauguración del Museo connotaría también otro valor simbólico. En su parecer (Proyecto de un Museo de Bellas Artes, 242) "Tendría lugar el día de la entrada a la capital de nuestro ejército victorioso", constituyéndose en un verdadero "arco triunfal", para recibir la tropa victoriosa en la Guerra del Pacífico.

La propuesta de Blanco había sido aplaudida por los editores de Revista Chilena, Miguel Luis Amunátegui y Diego Barros Arana ("Proyecto de un Museo de Bellas Artes", 236):

"Damos acogida con placer al interesante artículo del señor Blanco, uno de los artistas más inspirados, intelijentes e instruidos con que se enorgullece el Nuevo Mundo. Creemos que su proyecto debe ser protejido por todos aquellos que se interesen por el engrandecimiento del país. El arte es quizá la manifestación más bella i espléndida de la intelijencia humana. Un pueblo como el nuestro, que día a día progresa más i más, debe tener artistas y estímulos para los artistas. Ojalá se acepten las ideas del señor Blanco". 
Otro personaje que asociamos a la creación del Museo fue el coronel Marcos Maturana, conocido y estimado por los artistas por su sensibilidad y apoyo a distintas iniciativas, entre ellas el certamen que llevó su nombre. ${ }^{21}$

La publicación del proyecto redituó resultados rápidamente. El 31 de julio de 1880, el Ministro de Instrucción Pública Manuel García de la Huerta decretó el nombramiento de una comisión integra por el entonces coronel Marcos Segundo Maturana, Giovanni Mochi, profesor de la Escuela y José Miguel Blanco para hacerse a la misión de fundar el Museo. Al respecto, Arturo Blanco señaló (Blanco, Arturo, Biografia del escultor José Miguel Blanco 17), "Desde aquel entonces, Blanco i el coronel Maturana trabajaron con empeño en reunir cuanta obra de arte pertenecía al gobierno, dispersas en varios edificios públicos, i dieron término a su tarea, formando el Museo con 140 obras de arte, de las cuales el primer catálogo impreso, hizo Blanco".

Finalmente, el Museo fue inaugurado en los altos del Congreso Nacional por el Presidente de la República, Aníbal Pinto, el 18 de septiembre de 1880, en el marco de las celebraciones de Fiestas Patrias.

Una vez concretado el proyecto, la inequidad en la repartición de créditos y recompensas encendió nuevamente la polémica. Blanco representó esta deuda de gratitud por el escaso reconocimiento que se le hizo como actor de esta iniciativa. Su hijo Arturo (Blanco, Biografia..., 17), analizando este hecho, refiere el siguiente comentario: "A cargo de ese Museo, o más bien dicho, como Director, quedó Mochi; como portero Pedro Ruiz, i Blanco, como simple espectador. No alcanzó a ser siquiera portero de la obra que él había formado...". 22 En un recorte de prensa, de una publicación del 3 de julio de 1883 referida al Museo, Arturo Blanco escribe sobre ella, de puño y letra, "El canalla de Lira ni siquiera nombró a mi padre como iniciador y fundador del Museo". ${ }^{23}$

El compromiso de Blanco con el Museo fue permanente. Las actividades allí realizadas y el desarrollo del proyecto siempre formaron parte de los contenidos de $E l$ Taller Ilustrado. En una nota que Blanco envía a Eusebio Lillo en julio de 1887, bajo el pseudónimo de Jeme White, le señala su solidaridad para sobrellevar " ... la pesada carga que ha aceptado de resucitar al Museo de Bellas Artes que hoy duerme el sueño eterno de su ignorada tumba en los altos del Congreso". ${ }^{24}$ Blanco señala allí los distintos problemas que aquejan al Museo, entre ellos la luz, las condiciones de

\footnotetext{
${ }^{21}$ En la portada de El Taller Ilustrado, número 112, 2 de enero de 1888, se homenajeó a este benefactor. Un hermoso retrato del general Maturana, realizado por el ilustrador Fernando Rojas, es complementado con la siguiente leyenda: "Jeneral Maturana, Fundador del Primer Certamen Artístico en 1884, Homenaje de El Taller Ilustrado".

${ }^{22}$ Blanco, Arturo, Biografía del escultor José Miguel Blanco (publicada en los Anales de la Universidad de Chile), Imprenta Cervantes, Santiago de Chile 1912, página 18.

${ }^{23}$ La Época, "Exposición de Bellas Artes", 3 de julio de 1883. En archivo personal del autor de este artículo, Libro No 1 "Asuntos Artísticos 1843-1890”, perteneciente a Arturo Blanco.

${ }^{24}$ Blanco, José Miguel, "Color para las murallas interiores de un Museo", El Taller Ilustrado, julio de 1887.
} 
exhibición de las pinturas y las esculturas de bronce y de mármol. En otro número de El Taller Ilustrado, el 151 del 15 de octubre de $1888,{ }^{25}$ informó que la comisión que había nombrado el gobierno para tutelar el desarrollo del Museo había tratado de poner en remate público más de la mitad de las obras de la colección. La operación no se habría materializado por la intervención que él había hecho ante el Ministro de Instrucción Pública. El tema no termina allí; en el ejemplar 156, del 12 de noviembre de 1888, cuestiona nuevamente la marcha del Museo, especialmente la decisión tomada por la comisión de enviar parte de las obras a Chillán. ${ }^{26}$

Junto a la demanda por un Museo, José Miguel Blanco plantea también al Estado la exigencia de clases obligatorias de dibujo (Proyecto de un Museo de Bellas Artes, 238); "El día que el gobierno establezca museos i haga enseñar dibujo en las escuelas públicas; el día en que los particulares empiecen a proteger a los artistas, ese día Chile va a ser en América lo que es Italia en nuestra Europa: el país más artístico del continente".

Blanco defendió también la posibilidad de una educación artística para las mujeres. En un artículo suyo, "Dibujo: su enseñanza en los colegios", ${ }^{27}$ que dedicara a los "educacionistas i padres de familia", planteaba la necesidad de educar a las jóvenes chilenas en el dibujo, como una forma de asegurarse un medio de subsistencia y de realización personal.

\section{CONCLUSIÓN}

Consultada nuestra historiografía artística advertimos que la presencia de este escultor, sino omitida, aparece al menos algo desdibujada respecto de su mérito y trascendencia. ${ }^{28}$ Hubo una deuda con él en la cátedra de escultura que no tuvo en la Escuela, en reconocer en su momento el liderazgo que tuvo en la iniciativa de creación del Museo, en valorar sus aportes a la difusión y conocimiento de las Bellas Artes mediante la labor escritural que realizó. A ello debemos sumar el dato

\footnotetext{
${ }^{25}$ Blanco, José Miguel, "Las obras del Museo Nacional de Bellas Artes”, El Taller Ilustrado, número 151, 15 de octubre de 1888, no consigna número de página.

${ }^{26}$ Blanco, José Miguel, “¿Dónde está el Museo de Bellas Artes?”, El Taller Ilustrado, número 155, 12 de noviembre de 1888 , no consigna número de página.

${ }^{27}$ Blanco, José Miguel, "Dibujo: su enseñanza en los colegios", en Artes Plásticas en los Anales de la Universidad de Chile, Rosario Letelier y otros, Museo de Arte Contemporáneo, Editorial Universitaria, Santiago de Chile, 1993, página 30.

${ }^{28}$ Según su hijo Arturo, "El gobierno, que le había ofrecido un puesto de grabador en la Casa de Moneda, no le cumplió nunca esa promesa; de modo que tuvo que luchar toda su vida, como escultor, en un país como este, sin ningún sueldo fiscal i sin bien alguno de fortuna". Respecto de su labor como profesor agrega, "Todos los maestros escultores que hemos tenido: Plaza, Arias, González i Lagarrigue, han contado para ayudarse a su subsistencia, con una cátedra de escultura en la Escuela de Bellas Artes", excepto, por cierto, Blanco. Referencia "Don José Miguel Blanco. Escultor, Grabador de Medallas y Escritor de Bellas Artes", Letelier, Rosario, et al., Artes Plásticas en los Anales de la Universidad de Chile, Museo de Arte Contemporáneo, Editorial Universitaria, Santiago de Chile, 1993, páginas 114 y 115.
} 
de su alejamiento, en 1891, del cargo de Secretario del Consejo de Bellas Artes. Hay antecedentes de razones políticas en esta desafiliación.

En 1895 fue comisionado por el gobierno para realizar un viaje a Europa, para "imponerse de la organización industrial de las escuelas de escultura e informe al gobierno sobre el resultado de este estudio". Había interés en buscar nuevos modelos para la Clase de Escultura, para lo cual el artista "Debía enfocarse en la observación de nuevas disciplinas que fomentasen la instrucción de operarios, con el propósito de priorizar el ejercicio escultórico de aplicaciones ornamentales e industriales". ${ }^{29}$

En una de sus últimas cartas, dirigida a su esposa Petronila Arriagada, señala que este viaje fue hecho también en busca de salud. "Mi deseo de ver a París era dictado por la esperanza de mejoría, pero no para morir lejos de mi Patria". ${ }^{30}$ Regresa luego a Chile el 26 de noviembre de 1895, falleciendo el 4 de febrero de 1897 a la edad de 57 años.

En sus últimos días contó con la compañía generosa y solidaria de la Asociación de la Prensa, que lo había nombrado poco antes de su muerte como socio activo, exento de pago de cuotas. También con el apoyo de la Logia Masónica "Respetable Logia Justicia y Libertad $N^{\circ}$ 5", a la cual pertenecía, que había organizado algunas colectas para sufragar los gastos de su enfermedad.

En agosto de 1872 escribía desde Roma a su familia una carta que contenía una frase premonitoria de lo que iba a ser su vida, "En la vida, padre, en este valle de miserias, los caminos por donde andamos no están cubiertos de rosas, pero sí de espinas; por eso es que el hombre no puede dar un paso, sin clavarse hasta los huesos". 31

El primer homenaje formal que tuvo fue el 25 de septiembre de 1906, cuando un grupo de obreros funda en su recuerdo la Sociedad de Canteros y Marmolistas "José Miguel Blanco", cuyo objeto fue el ahorro y la protección mutua.

$$
\begin{array}{r}
\text { Universidad de Talca* } \\
\text { Instituto de Estudios Humanisticos } \\
2 \text { Norte } N^{\circ} 685 \text { Talca (Chile) } \\
\text { pzamoper@utalca.cl } \\
\text { Universidad de Playa Ancha** } \\
\text { Facultad de Artes } \\
\text { Avda. Playa Ancha } N^{o} \text { 850. Valparaíso (Chile) } \\
\text { Universidad de Chile*** } \\
\text { Facultad de arquitectura y urbanismo } \\
\text { Portugal } N^{\circ} 86 . \text { Santiago (Chile) }
\end{array}
$$

\footnotetext{
${ }^{29}$ Decreto (envío de José Miguel Blanco a Europa), 7 de junio de 1895, Archivo Nacional, Fondo Ministerio de Educación, Decretos 1886-1896, vol. 656, número 1764.

${ }^{30}$ Carta a su esposa Petronila Arriagada de Blanco, de París, 12 de septiembre de 1895, en Blanco, Arturo, Cartas del escultor José Miguel Blanco. Santiago de Chile, Imprenta Las Artes Mecánicas, 1907:96.

${ }^{31}$ Blanco, Arturo, Cartas del escultor José Miguel Blanco, página 62.
} 


\section{OBRAS CITADAS}

Berríos, Pablo., et al. Del taller a las aulas, la institución moderna del arte en Chile (1797-1910). Estudios de Arte, Impresión. Santiago de Chile: Gráfica LOM, 2009.

Blanco, José Miguel. "Proyecto de un Museo de Bellas Artes", en Revista Chilena, 1879 (tomo 15). Santiago de Chile.

------- El Taller Ilustrado, "El Salón de la Unión Artística”, 28 de febrero de 1887.

------ "Color para las murallas interiores de un Museo", El Taller Ilustrado, número 89, 7 julio de 1887

------ "Las obras del Museo Nacional de Bellas Artes", El Taller Ilustrado, número 151,15 de octubre de 1888.

------ “Dónde está el Museo de Bellas Artes?”, El Taller Ilustrado, número 155, 12 de noviembre de 1888 .

------ “Por qué no hai arte nacional en Chile?”, El Taller Ilustrado. Número 157, 26 de noviembre de 1888.

------ "Lasciate Ogni Speranza...", El Taller Ilustrado, número 179, 13 de mayo de 1889.

Blanco, Arturo. Cartas del escultor José Miguel Blanco. Santiago de Chile: Imprenta Las Artes Mecánicas, 1907.

------ Biografía del escultor José Miguel Blanco. Santiago de Chile: Imprenta Cervantes, 1912.

------ Biografía del escultor José Miguel Blanco (publicada en los Anales de la Universidad de Chile). Santiago de Chile: Imprenta Cervantes, 1912.

Carvacho, Víctor. Historia de la escultura en Chile. Santiago de Chile: Editorial Andrés Bello, 1983.

"Exposición de Bellas Artes", La Época, 3 de julio de 1883. En archivo personal del autor de este artículo, Libro $\mathrm{N}^{\circ} 1$ "Asuntos Artísticos 1843-1890", perteneciente a Arturo Blanco.

Letelier, Rosario., et al., Artes Plásticas en los Anales de la Universidad de Chile, Museo de Arte Contemporáneo. Santiago de Chile: Editorial Universitaria, 1993.

Melcherts, Enrique. Introducción a la escultura chilena, Impresión en Talleres Ferrand e Hijos Ltda., Valparaíso, Chile, 1982.

Ortega, Pascual., et al., "El señor Vicente Grez i sus críticas sobre arte en La Época", El Taller Ilustrado, número 108, 28 de noviembre de 1887. 